\title{
FILM PEMBELAJARAN TARI JANGER KOLOK (TULI BISU) UNTUK GENERASI PENYANDANG KOLOK DI DESA BENGKALA
}

\author{
Ni Putu Tina Resdiana ${ }^{1}$, I Ketut Resika Arthana ${ }^{2}$, \\ I Made Agus Wirawan ${ }^{3}$ \\ Jurusan Pendidikan Teknik Informatika, Fakultas Teknik Dan Kejuruan, Universitas Pendidikan Ganesha
}

\begin{abstract}
Abstrak
Pengembangan Media Film Pembelajaran Tari Janger Kolok (Tuli Bisu) Untuk Generasi Penyandang Kolok (Tuli Bisu) di Desa Bengkala. Di Desa Bengkala terselip sesuatu yang menarik untuk ditelusuri. Ternyata, lebih dari $2 \%$ penduduk saat ini adalah penyandang tuli bisu. Masyarakat Desa Bengkala menyebutnya kolok. Menurut data yang di peroleh dari Kantor Kepala Desa, dulunya penyandang tuli bisu di Desa Bengkala ini hanya ada 1 orang dan kemudian meninggkat sehingga berjumlah sekitar $11 \mathrm{KK}$ sampai saat ini jumlahnya sudah meningkat lebih dari 47 jiwa.Film ini merupakan sebuah film yang mempublikasikan kelestarian dari tarian yang sangat unik dan sangat menarik. Sehingga, sangat perlu dikembangkan suatu film pembelajaran agar nantinya dapat berfungsi bagi generasi kolok yang nantinya akan meneruskan kebudayaan ini.

Dalam pembuatan Film Pembelajaran Tari Janger Kolok ini, metode penelitian atau perancangan Film Pembelajaran Tari Janger Kolok menggunakan model penelitian ADDIE. Model pengembangan ADDIE merupakan model desain pembelajaran yang berlandasan pada pendekatan sistem yang efektif dan efisien serta prosesnya yang bersifat interaktif yakni hasil evaluasi setiap fase dapat membawa pengembangan pembelajaran ke fase selanjutnya. Hasil akhir dari suatu fase merupakan produk awal bagi fase berikutnya. Model ini terdiri atas 5 fase atau tahap utama yaitu 1) Analyze (Analisis), 2) Design (Desain), 3) Develop (Pengembangan), 4) Implement (Implementasi), 5) Evaluate (Evaluasi).

Berdasarkan angket penilaian dari ahli materi, ahli media dan responden media film maka diperoleh hasil, uji materi mendapat nilai presentase sebesar $86 \%$ jika dikonversi media mendapat kategori baik dan tidak perlu direvisi, dari uji ahli media I memperoleh presentase sebesar $90 \%$ dan uji ahli media II memperoleh presentase sebesar $85 \%$, uji ahli media III memperoleh presentase sebesar $83 \%$ jika di rata-rata dan dikonversi media mendapat nilai $86 \%$ baik dan tidak perlu direvisi dan berdasar hasil uji responden mendapat rerata presentase sebesar $90 \%$ jika dikonversi, maka media mendapat predikat sangat baik.

Hasil akhir berupa Film Pembelajaran Tari Janger Kolok berformat DVD. Film ini diharapkan bisa memberikan tontonan yang menarik dan mendidik bagi penonton khususnya anak-anak penyandang kolok (Tuli Bisu) di Desa Bengkala. Selain itu dengan adanya pembuatan film ini diharapkan bisa merangsang para pembuat media pembelajaran untuk membuat media yang lebih berkualitas. Sehingga dengan adanya media yang berkualitas bisa meningkatkan motivasi dan prestasi dalam mengembangkan diri.
\end{abstract}

Kata kunci : Film, Pembelajaran Tari Janger Kolok, ADDIE

\begin{abstract}
Development of Learning Dance Media Film Janger Kolok (Deaf Mute) For Generation Kolok Persons (Deaf Dumb) Bengkala Village. In the village tucked Bengkala something interesting to explore. Apparently, more than $2 \%$ of the population today is with a deaf mute. Village Community Bengkala kolok call. According to data obtained from the Office of the Chief of the village, formerly deaf mute persons in the village Bengkala there is only one person and then increase that amount to about 11 families to date the number has increased by more than 47 deaths. This film is a film that publish sustainability of the dances are very unique and very attractive. So, it is necessary to develop a learning movie that can later serve kolok generations who will continue this culture.

In making the film Dance Lessons Janger this Kolok, research methods or design Film Dance Lessons Janger Kolok ADDIE model study. ADDIE development model is a model of instructional design
\end{abstract}

Film Pembelajaran Tari Janger Kolok..... (Ni Putu Tina Resdiana, I Ketut Resika Arthana, I Made Agus Wirawan) 
approach is grounded in an effective and efficient systems and processes that are interactive namely the evaluation result of each phase can lead to the development of the next phase of learning. Final results of a phase is the initial product for the next phase. This model consists of five main phases or stages: 1) Analyze (Analysis), 2) Design (Design), 3) Develop (Development), 4) Implement (Implementation), 5) Evaluate (evaluation). Based on the assessment questionnaire matter experts, media experts and media respondents films of the obtained results, the judicial scored a percentage of $86 \%$ if the media gets converted both category and do not need to be revised, from the media expert test I earn a percentage of $90 \%$, test media expert II to obtain a percentage of $85 \%$ and test media expert III to obtain a percentage of $83 \%$, if the converted media gets good grades and does not need to be revised based on the results of the test and the average percentage of respondents received by $80 \%$ if converted, then the media gets a good rating. The end result in the form of film Janger Kolok Dance Lessons DVD format. The film is expected to provide an interesting and educational spectacle for spectators especially children with kolok (Deaf Dumb) Bengkala Village. In addition to the making of the film is expected to stimulate the learning media makers to create higher quality media. So with the quality media can increase motivation and achievement in developing themselves.

Keywords: Film, Dance Lessons Janger Kolok, ADDIE

\section{PENDAHULUAN}

Desa merupakan tempat pemukiman penduduk yang masih alami. Pada umumnya setiap desa memiliki tradisi dan adat istiadat. Selain itu, desa juga di indentikan dengan tempat pemukiman penduduk yang masih asri yang dideskripsikan memiliki kekayaan alam yang berlimpah, pemandangan yang bagus, dan lain sebagainya Indrizal (2012:06). Di Bali Utara, terdapat banyak desa yang memiliki keunikan tersembunyi. Tidak banyak orang yang mengetahui keberadaan desa tersebut. Salah satunya Desa Bengkala. Di Desa Bengkala terselip sesuatu yang menarik untuk ditelusuri. Ternyata, lebih dari $2 \%$ penduduk saat ini adalah penyandang tuli bisu. Masyarakat Desa Bengkala menyebutnya kolok. Menurut data yang di peroleh dari Kantor Kepala Desa, dulunya penyandang tuli bisu di Desa Bengkala ini hanya ada 1 orang dan kemudian meninggkat sehingga berjumlah sekitar $10 \mathrm{KK}$ sampai saat ini jumlahnya sudah meningkat lebih dari 47 jiwa.

Berdasarkan permasalahan yang telah dijelaskan, maka peneliti menerapkan teknologi informasi untuk mendukung Film Pembelajaran Janger Kolok (Tuli Bisu) Untuk Generasi Penyandang Kolok (Tuli Bisu) di Desa Bengkala dalam mempublikasikan kelestarian dari tarian yang sangat unik dan sangat menarik. Sehingga, sangat perlu dikembangkan suatu film pembelajaran agar nantinya dapat berfungsi bagi generasi kolok yang nantinya akan meneruskan kebudayaan ini.

\section{KAJIAN TEORI}

A. Pengertian Desa

Desa adalah suatu kesatuan hukum dimana bermukim sutau masyarakat yang berkuasa dan masyarakat tersebut mengadakan pemerintah sendiri. Sedangkan pengertian desa dalam kehidupan sehari-hari atau secara umum sering di istilahkan dengan kampung, yaitu suatu daerah yang letaknya jauh dari keramaian kota, yang dihuni sekelompok masyarakat dimana sebagian besar mata pencahariannya sebagai petani sedangkan secara administratif desa adalah yang terdiri dari satu atau lebih atau dusun di gabungkan hingga menjadi suatu daerah yang berdiri sendiri atao berhak mengatur rumah tangga sendiri atau otonomi (Kartohadikusumo, 2005).

\section{B. Pengertian Film}

Film adalah gambar-hidup yang juga sering disebut movie. Film secara kolektif sering disebut sebagai sinema. Sinema itu sendiri bersumber dari kata kinematik atau gerak.

\section{Sejarah Munculnya Janger Kolok di Desa Bengkala}

Sejarah munculnya Janger Kolok ini menurut Ketut Kanta (45 tahun, 10 Januari 2013) yang mendirikan Janger Kolok tersebut adalah (Almarhum) Wayan Nedeng, beliau adalah penduduk asli Desa Bengkala dan beliau adalah orang normal. Janger Kolok ini didirikan pada tahun 1969 sampai dengan 1970-an. Latar belakang pendirian jager kolok 
tersebut karena keunikan dari jangernya itu nyanyian yang dinyanyikan tidak sama dengan nyanyian seperti janger biasanya janger ini hanya menggunakan bahasa isyarat.

\section{METODE PENELITIAN}

\section{A. Perancangan Film}

Metode penelitian ini menggunakan pendekatan penelitian dan pengembangan (Research and Development). Menurut Sugiyono (dalam Rahardini, 2013) metode penelitian dan pengembangan merupakan metodepenelitian yang digunakan untuk menghasilkan produk tertentu dan menguji keefektifan produk tersebut. Model pengembangan dalam penelitian ini menggunakan model Analysis Design Development Implementation Evaluation (ADDIE). Model ini dipilihkarena model ADDIE sering digunakan untuk menggambarkan pendekatanyang berurutan dan interaktif. Selain itu, model ADDIE merupakan model pembelajaran yang bersifat umum dan sesuai digunakan untuk penelitian pengembangan.

\section{B. Analisis}

Pada tahap analisis dilakukan analisis kebutuhan sistem yang sangat di butuhkan dalam rangka maksimalisasi kegiatan produksi , apakah sistem yang ada telah sesuai dengan kebutuhan atau belum. Karena kebutuhan sistem akan mendukung tercapainya visi dan misi sebuah rumah produksi. Fungsi sistem yang penulis buat ini adalah untuk memberikan kemudahan bagi penggemar pembuat film untuk membuat film pembelajaran.

\section{Desain}

Dalam tahapan desain pada metode ADDIE dilakukan pra produksi pembuatan film. Pada tahap Pra Produksi film ini belum dilakukan perekaman (shooting), tetapi persiapan/perencanaan yang akan diperlukan dalam pembuatan film ini, adapun yang direncanakan sebagai berikut.

1) Ide Cerita
Ide cerita merupakan hal yang mendasar untuk mengembangkan sebuah karya media film pembelajaran. Ide cerita dari Film Pembelajaran Janger Kolok (Tuli Bisu) Untuk Generasi Penyandang Kolok (Tuli Bisu) di Desa Bengkala terinspirasi dari banyaknya penyandang kolok (tuli bisu) yang masih anak-anak di Desa Bengkala, mereka nantinya yang akan meneruskan generasi Tari Janger Kolok.

2) Penulisan naskah/sinopsis

Penulisan naskah atau sipnosis merupakan ringkasan cerita secara garis besarnya. Pembuatan sinopsis di maksudkan untuk menjaga dan mempertahankan sebuah cerita untuk tetap berada dalam jalurnya, tidak keluar dari alur cerita yang di inginkan pengarang. Berikut sinopsis Film Pembelajaran Janger Kolok (Tuli Bisu) Untuk Generasi Penyandang Kolok (Tuli Bisu) di Desa Bengkala.

3) Penulisan Storyboard

Storyboard adalah sketsa gambar yang disusun berurutan sesuai dengan naskah, dengan storyboard kita dapat menyampaikan ide cerita kita kepada orang lain dengan lebih mudah, karena kita dapat mempengaruhi persepsi pembaca sama dengan alur cerita. Salah satu tahapan penting dalam produksi film adalah membuat storyboard, setelah sutradara dan pengarah fotografi membahas sebuah adegan mereka kemudian menterjemahkan gagasan mereka dalam gambar. Disitu terbentuklah rancangan-rancangan shooting, dan ketika dirasa ada sesuatau yang kurang pas atau ada kendala-kendala dalam pengambilan gambar nantinya segera dapat dilakukan revisi.

4) Melakukan casting atau memilih pemeran dalam cerita. Sebelum melakukan perekaman (shooting) terlebih dahulu perlu diadakan pemilihan pemeran yang disesuaikan dengan karakter dicerita. Pemeran yang sesuai dengan karakter akan sangat berpengaruh pada keberhasilan produksi film.

5) Menetapkan lokasi dan latar yang akan digunakan. Dalam menetapkan lokasi dan latar dari film yang dibuat maka harus 
disesuaikan dengan cerita atau naskah yang dibuat. Kesesuaian lokasi dan latar dalam pembuatan film sangat berpengaruh pada keberhasilan produksi.

\section{Pengembangan (development)}

Pada fase ini dilakukan tahapan-tahapan yang terdapat dalam proses produksi dan pasca produksi dari media Film Pembelajaran Janger Kolok (Tuli Bisu) Untuk Generasi Penyandang Kolok (Tuli Bisu) di Desa Bengkala.

\section{a. Produksi}

Pada tahap produksi Film Pembelajaran Janger Kolok (Tuli Bisu) Untuk Generasi Penyandang Kolok (Tuli Bisu) di Desa Bengkala dibuat sesuai kebutuhan dari pra produksi yang telah dirancang. Adapun hal yang dilakukan di tahap produksi adalah sebagai berikut. Merekam (shooting) adeganadegan film dalam scene yang sudah direncanakan pada tahap pra produksi.

\section{b. Pasca Produksi}

Pengkoposisian dan editing dalam pembuatan sebuah film adalah hal yang sangat utama. Karena pada tahap inilah adengan - adegan yang sudah direkam kemudian disatukan dan diberi efek transisi ataupun efek suara. Sehingga akan menambah daya tarik menonton dan menyimak materi yang ada didalam film.

\section{E. Implementasi}

Pada fase ini, film pembelajaran janger kolok yang dibuat akan di uji cobakan menggunakan windows media player dengan cara dipertontonkan kepada penyandang kolok (tuli bisu) khususnya yang anak-anak sehingga diketahui respon penyandang kolok anak-anak terhadap film pembelajaran janger kolok. Pada fase ini pemain film janger kolok di beritahukan bagaimana nantinya adegan yang mereka perankan di film janger kolok, apa saja yang perlu mereka siapkan nantinya sebelum pengambilan video di lakukan.

\section{F. Evaluasi}

Pada tahap evaluasi akan dibagi menjadi evaluasi formatif dan evaluasi sumatif. Evaluasi formatif ada disetiap tahapan ADDIE yaitu masukan dari ahli media pembelajaran, ahli desain pembelajaran dan ahli isi mata pelajaran sebelum produk tersebut diimplementasikan di Desa Bengkala.
Adapun Ahli gerakan tari yang menjadi validator tarian adalah guru tari di SD N 1 Desa Bengkala yaitu Ni Nyoman Sri Mayuni, S.Pd. Ahli desain pembelajaran dan ahli media pembelajaran merupakan dosen di Jurusan Pendidikan Teknik Informatika Undiksha yaitu I Ketut Resika Arthana, S.T., M.Kom, Made Agus Wirawan, S.Kom, M.Cs, dan I Gede Sri Agus Putrawan, A.Md. Sedangkan tahap evaluasi sumantif yaitu memberikan peluang umpan balik dari pengguna.

Pada evaluasi formatif ditunjukan oleh ahli tarian yaitu guru, ketika memberikan masukan tentang tarian yang akan dimuat di dalam film pembelajaran yang akan dibuat. Kemudian dari ahli desain memberikan masukan terhadap alur cerita film pembelajaran, pemilihan tokoh yang tepat untuk film pembelajaran dan pada pengembangan peneliti meminta masukan terhadap guru sebagai isi mata pelajaran terhadap film yang dikembangkan untuk mendapatkan kesesuaian dengan tujuan pembelajaran. Sedangkan evaluasi sumantif dalam hal ini yaitu peneliti melihat respon penyandang kolok (tuli bisu) yang masih anak-anak terhadap film pembelajaran yang telah diimplementasikan dalam pembelajaran tari janger kolok

\section{PENGEMBANGAN IMPLEMENTASI DAN PENGUJIAN}

\section{A. Implementasi Film Pembelajaran Tari Janger Kolok}

Pada tahap implementasi akan dipaparkan beberapa hal yang berkaitan dengan implementasi Film Pembelajaran Janger Kolok (Tuli Bisu) Untuk Generasi Penyandang Kolok (Tuli Bisu) di Desa Bengkala, yaitu Implementasi Produksi, Implementasi Pasca Produksi, dan Implementasi Pra Produksi.

\section{Implementasi Produksi}

Pada tahap implementasi produksi menggunakan perangkat keras yaitu Camera Canon 1100D, Handycam sonyDCR-SX22, dan tripod. Dalam kegiatan produksi dilakukan proses perekaman/shooting film.

2. Implementasi Pasca Produksi 
Pada tahap implementasi pasca produksi menggunakan perangkat lunak Pinnacle Studio 12. Berikut beberapa tampilan pasca produksi Film Pembelajaran Tari Janger Kolok (Tuli Bisu) Untuk Generasi Penerus Penyandang Kolok (Tuli Bisu) di Desa Bengkala.

3. Implementasi Pra Produksi

Pada tahap implementasi pra produksi akan dipaparkan mengenai Spesifikasi Perangkat Lunak, Spesifikasi Perangkat keras, implementasi lingkungan shooting, implementasi tokoh, implementasi gambar pendukung, dan implementasi storyboard. Tampilan - tampilan Film Pembelajaran Tari Janger Kolok (Tuli Bisu) Untuk Generasi Penyandang Kolok (Tulis Bisu) di Desa Bengkala.

4. Implementasi Tokoh Film

\begin{tabular}{|c|c|c|c|}
\hline 10 & Nama gambar & Implementasi Gambar & Keterangan \\
\hline . & $\begin{array}{l}\text { Gambar } 4.1 \text { Tampak } \\
\text { Depan Tokoh Kolok } \\
\text { Putu Suara }\end{array}$ & $\begin{array}{l}\text { Gambar } 4.1 \text { Implementasi } \\
\text { Tampak Depan Tokoh } \\
\text { Kolok Putu }\end{array}$ & $\begin{array}{l}\text { Tampilan: Kolok Putu } \\
\text { Background: di dalam rumah } \\
\text { kolok putu } \\
\text { Shooting kamera: Medium } \\
\text { shoot }\end{array}$ \\
\hline . & $\begin{array}{l}\text { Gambar 4.2 Tampak } \\
\text { Depan Tokoh Kolok } \\
\text { Ketut Aniana }\end{array}$ & $\begin{array}{l}\text { Gambar } 4.2 \text { Implemenrasi } \\
\text { Tampak Depan Tokoh } \\
\text { Kolok Ariana }\end{array}$ & $\begin{array}{l}\text { Tampilan: Kolok Aniana } \\
\text { Background : tempat berias } \\
\text { tanj janger kolok } \\
\text { Shooting kamera : fullshoot }\end{array}$ \\
\hline 3. & $\begin{array}{l}\text { Gambar } 4.3 \text { Tampak } \\
\text { Depan Tokoh Kolok } \\
\text { Cening }\end{array}$ & $\begin{array}{l}\text { Gambar } 4.3 \text { Implemenrasi } \\
\text { Tampak Depan Tokoh } \\
\text { Kolok Cening }\end{array}$ & $\begin{array}{l}\text { Tampilan: Kolok Cening } \\
\text { Background : tempat berias } \\
\text { tani janger kolok } \\
\text { Shooting kamera : Medium } \\
\text { shoot }\end{array}$ \\
\hline & $\begin{array}{l}\text { Gambar } 4.4 \text { Tampak } \\
\text { Depan Tokoh Kolok } \\
\text { Suamadi }\end{array}$ & $\begin{array}{l}\text { Gambar } 4.4 \text { Implemenrasi } \\
\text { Tampak Depan Tokoh } \\
\text { Kolok Suamadi }\end{array}$ & $\begin{array}{l}\text { Tampilan: Kolok Suamadi } \\
\text { Background : tempat benias } \\
\text { tari janger kolok } \\
\text { Shooting kamera : fullshoot }\end{array}$ \\
\hline
\end{tabular}

B. Hasil Angket Tari Janger Kolok Berdasarkan Rumus, rerata persentase yang diperoleh untuk uji lapangan yang dilakukan pada 10 penyandang kolok (tuli bisu) diperoleh skor $80 \%$. Selanjutnya rerata persentase tersebut bila dikonversikan ke dalam tabel konversi berada dalam kualifikasi baik dan tidak perlu direvisi.

Berdasarkan rekaptulasi penilaian dari masing-masing responden. Detail Hasil Angket Uji Ahli Materi. Detail Hasil Angket Uji Ahli Media 1, Detail Hasil
Angket Uji Ahli Media 2, Detail Hasil Angket Uji Ahli Media 3, Detail Hasil Angket Uji Lapangan dapat disimpulkan bawa rerata persentase keseluruahan adalah $86 \%$. Selanjutnya rerata persentase tersebut bila dikonversikan ke dalam tabel konversi berada dalam kualifikasi baik.

\section{SIMPULAN}

Berdasarkan penelitian Film Pembelajaran Tari Janger Kolok (Tuli Bisu) Untuk Generasi Penyandang Kolok (Tuli Bisu) di Desa Bengkala ini maka dapat diambil kesimpulan yaitu:

1. Pembuatan Film Pembelajaran Tari Janger Kolok (Tuli Bisu) Untuk Generasi Penyandang Kolok (Tuli Bisu) di Desa Bengkala menggunakan metode penelitian ADDIE yang terdiri dari 5 tahap. Tahap pertama adalah tahap analyze yaitu tahap awal yang digunakan dalam desain pembelajaran dalam pembuatan film ini seperti kebutuhan fungsional, kebutuhan non fungsional. Tahap kedua adalah tahap design yaitu, dilakukan pra produksi pembuatan video/film seperti ide cerita, penulisan naskah, casting pemeran, lokasi, jadwal pengerjaan, serta pembuatan storyboard. Tahap ketiga adalah development yaitu dilakukan tahapan-tahapan yang terdapat dalam proses produksi dan pasca produksi film pembelajaran. Tahap produksi seperti proses shooting, sedangkan di pasca produksi yakni proses editing. Tahap keempat adalah implementation adalah tahap uji coba terhadap anak-anak penyandang kolok (Tuli Bisu) di Desa Bengkala Tahap kelima adalah evaluation merupakan tahap dimana tindakan yang dilakukan bertujuan untuk mengetahui keberhasilan film pembelajaran yang dikembangkan.

2. Dalam proses pembuatan film pembelajaran menggunakan software pinnacle studio 12 digunakan untuk menyambungkan, mengedit dan render 
video, windows media player digunakan untuk melihat hasil rendering dan adobe photosop CS3 digunakan mengedit gambar yang digunakan di dalam film.

3. Dalam Film Pembelajaran Tari Janger Kolok (Tuli Bisu) Untuk Generasi Penyandang Kolok (Tuli Bisu) di Desa Bengkala menggunakan 5 orang pemain dan setting tempat yaitu di rumah Kolok Putu Suara, jalan raya dusun kajanan Desa Bengkala, Kantor kepala desa, dan Pura Bale Agung Desa Bengkala.

4. Berdasarkan angket penilaian dari ahli materi, ahli media dan responden media film maka diperoleh hasil, uji materi mendapat nilai presentase sebesar $86 \%$ jika dikonversi media mendapat kategori baik dan tidak perlu direvisi, dari uji ahli media I memperoleh presentase sebesar $90 \%$, uji ahli media II sebesar $85 \%$, dan uji ahli media III memperoleh presentase sebesar $83 \%$ jika dikonversi media mendapat nilai baik dan tidak perlu direvisi dan berdasar hasil uji responden mendapat rerata presentase sebesar $90 \%$ jika dikonversi, maka media mendapat predikat sangat baik.

\section{Saran}

Berdasarkan hasil penelitian pengembangan dan kesimpulan, saran yang dapat diberikan kepada pembaca adalah sebagai berikut.

1. Dalam Film Pembelajaran Tari Janger Kolok (Tuli Bisu) Untuk Generasi Penyandang Kolok (Tuli Bisu) di Desa Bengkala yang dalam proses renderingnya di pinnacle studio 12 hendaknya menggunakan Proccesor, RAM dan VGA yang spesifikasinya lebih tinggi sehingga menjadi bisa lebih cepat dan hasilnya lebih bagus.

2. Dalam proses Film Pembelajaran Tari Janger Kolok (Tuli Bisu) Untuk Generasi Penyandang Kolok (Tuli Bisu) di Desa Bengkala juga harus didukung oleh kamera yang berkualitas tinggi sehingga menghasilkan video/film dengan kualitas tinggi pula.

3. Dalam pemilihan pemeran film harus disesuaikan dengan adegan film dan kemampuan acting sehingga akan membuat proses produksi lebih cepat dan efisien.

4. Dalam proses shooting diperlukan alat perekam suara yang bagus untuk menghindari gangguan suara yang tidak diinginkan atau mencari tempat sepi dengan gangguan suara yang minim.

\section{DAFTAR PUSTAKA}

Indrizal, Edi. 2006. "Memahami Konsep Perdesaan dan Tipologi Desa di Indonesia".

Kartohadikusumo, S. 2005. "Pengertian Desa dan Kota".

Mailiana, Nur. 2013. "Keefektifan Model Pembelajaran ADDIE Terhadap HasilBelajar Matematika Pada Siswa Kelas $V$ SD Negeri Gringsing 01 BatangTahun 2012/2013. Skripsi (tidak diterbitkan). Program Studi Pendidikan Guru Sekolah Dasar, IKIP PGRI Semarang". 
